\title{
Non-stomatal exchange in ammonia dry deposition models: comparison of two state-of-the-art approaches
}

\author{
Frederik Schrader $^{1}$, Christian Brümmer ${ }^{1}$, Chris R. Flechard ${ }^{2}$, Roy J. Wichink Kruit ${ }^{3}$, Margreet C. van Zanten ${ }^{3}$, \\ Undine Zöll $^{1}$, Arjan Hensen ${ }^{4}$, and Jan Willem Erisman ${ }^{5,6}$ \\ ${ }^{1}$ Thünen Institute of Climate-Smart Agriculture, Braunschweig, Germany \\ ${ }^{2}$ Instiute National de la Recherche Agronomique (INRA), Agrocampus Ouest, UMR1069 SAS, Rennes, France \\ ${ }^{3}$ National Institute for Public Health and the Environment (RIVM), Bilthoven, the Netherlands \\ ${ }^{4}$ Energy Research Centre of the Netherlands (ECN), Petten, the Netherlands \\ ${ }^{5}$ Cluster Earth and Climate, Department of Earth Sciences, Vrije Universiteit Amsterdam, Amsterdam, the Netherlands \\ ${ }^{6}$ Louis Bolk Institute, Driebergen, the Netherlands \\ Correspondence to: Frederik Schrader (frederik.schrader@thuenen.de)
}

Received: 12 May 2016 - Published in Atmos. Chem. Phys. Discuss.: 22 June 2016

Revised: 12 October 2016 - Accepted: 18 October 2016 - Published: 31 October 2016

\begin{abstract}
The accurate representation of bidirectional ammonia $\left(\mathrm{NH}_{3}\right)$ biosphere-atmosphere exchange is an important part of modern air quality models. However, the cuticular (or external leaf surface) pathway, as well as other non-stomatal ecosystem surfaces, still pose a major challenge to translating our knowledge into models. Dynamic mechanistic models including complex leaf surface chemistry have been able to accurately reproduce measured bidirectional fluxes in the past, but their computational expense and challenging implementation into existing air quality models call for steady-state simplifications. Here we qualitatively compare two semi-empirical state-of-the-art parameterizations of a unidirectional non-stomatal resistance $\left(R_{\mathrm{W}}\right)$ model after Massad et al. (2010), and a quasi-bidirectional nonstomatal compensation-point $\left(\chi_{\mathrm{w}}\right)$ model after Wichink Kruit et al. (2010), with $\mathrm{NH}_{3}$ flux measurements from five $\mathrm{Eu}-$ ropean sites. In addition, we tested the feasibility of using backward-looking moving averages of air $\mathrm{NH}_{3}$ concentrations as a proxy for prior $\mathrm{NH}_{3}$ uptake and as a driver of an alternative parameterization of non-stomatal emission potentials $\left(\Gamma_{\mathrm{w}}\right)$ for bidirectional non-stomatal exchange models. Results indicate that the $R_{\mathrm{w}}$-only model has a tendency to underestimate fluxes, while the $\chi_{\mathrm{w}}$ model mainly overestimates fluxes, although systematic underestimations can occur under certain conditions, depending on temperature and ambient $\mathrm{NH}_{3}$ concentrations at the site. The proposed $\Gamma_{\mathrm{w}}$ parameterization revealed a clear functional relationship be-
\end{abstract}

tween backward-looking moving averages of air $\mathrm{NH}_{3}$ concentrations and non-stomatal emission potentials, but further reduction of uncertainty is needed for it to be useful across different sites. As an interim solution for improving flux predictions, we recommend reducing the minimum allowed $R_{\mathrm{W}}$ and the temperature response parameter in the unidirectional model and revisiting the temperature-dependent $\Gamma_{\mathrm{w}}$ parameterization of the bidirectional model.

\section{Introduction}

Reactive nitrogen $\left(\mathrm{N}_{\mathrm{r}}\right)$ deposition can contribute to a number of adverse environmental impacts, including ecosystem acidification, shifts in biodiversity, or climate change (Erisman et al., 2013). Breakthroughs in the measurement of biosphere-atmosphere exchange of ammonia $\left(\mathrm{NH}_{3}\right)$, the major constituent of $\mathrm{N}_{\mathrm{r}}$ (Sutton et al., 2013), have been made in the recent past with the rising availability of highfrequency measurement devices that can be used within the eddy covariance method (e.g., Famulari et al., 2004; Ferrara et al., 2012; Zöll et al., 2016), and a large body of flux measurements using other measurement techniques, e.g., the aerodynamic gradient method, has emerged from large-scale projects such as NitroEurope (Sutton et al., 2011). These measurements, however, are usually only representative for a specific location and difficult to interpolate in 
space. Surface-atmosphere exchange schemes that predict ammonia exchange fluxes from measured or modeled concentrations and micrometeorological conditions are used on both the local scale and within large-scale chemical transport models (CTMs). Following the discovery of the ammonia compensation point (Farquhar et al., 1980), today these models are able to reproduce bidirectional exchange fluxes, i.e., both emission and deposition of ammonia, and typically feature at least a stomatal and a non-stomatal leaf surface pathway. The addition of a soil- or leaf-litter pathway by $\mathrm{Ne}-$ mitz et al. (2001) has been recognized as an optimal compromise between model complexity and accuracy of the flux estimates (Flechard et al., 2013), although some uncertainties in the treatment of the ground layer still prevail.

While the representation of the stomatal pathway has received much attention in the literature due to its importance not only for ammonia, but also for a large number of other atmospheric constituents, especially carbon dioxide $\left(\mathrm{CO}_{2}\right)$ and water vapor $\left(\mathrm{H}_{2} \mathrm{O}\right)$ (e.g., Jarvis, 1976; Farquhar and Sharkey, 1982; Ball et al., 1987), modeling non-stomatal exchange is still subject to considerable uncertainty (Burkhardt et al., 2009). Ammonia is highly soluble in water and thus readily deposits to water layers on the leaf cuticle and on any other environmental surface following precipitation events, condensation of water vapor, or due to the presence of hygroscopic particles on the surface. This characteristic behavior is typically modeled with an exponential relative humidity response function as a proxy for canopy wetness, where a high relative humidity results in low non-stomatal resistances, and vice versa (e.g., Sutton and Fowler, 1993; Erisman et al., 1994). A self-limiting effect of ambient ammonia concentrations on the deposition process, due to saturation effects and an increase in surface $\mathrm{pH}$, has been observed in experiments (Jones et al., 2007a, b; Cape et al., 2008) and implemented in some non-stomatal exchange models (e.g., Wichink Kruit et al., 2010). Additionally, re-emission events during evaporation of leaf surface water layers have been measured in the field, which hints at the limits of these classically static and unidirectional approaches (Wyers and Erisman, 1998). Sutton et al. (1998) and Flechard et al. (1999) have successfully reproduced measurements of these events on the field scale by modeling the water films as charged capacitors for ammonia emissions; however, these models need complex dynamic leaf chemistry modules, which drastically increase computational expense and necessary input variables and consequently limit their applicability in large scale simulations. Wichink Kruit et al. (2010) developed a static hybrid model featuring a non-stomatal compensation-point approach in order to simplify the model calculations and as an important step towards the use of a bidirectional non-stomatal exchange paradigm within large scale CTMs. In this paper, we compare the performance of two state-of-the-art parameterizations of non-stomatal exchange: the unidirectional approach of Massad et al. (2010) and the quasi-bidirectional approach of Wichink Kruit et al. (2010). The Massad et al. (2010) param- eterization has received widespread acceptance in the community, with 53 citations according to the literature database "Thomson Reuters Web of Science" at the time of writing this article, and variants of it have been applied in numerous studies, e.g., recently in Shen et al. (2016), Móring et al. (2016), Zöll et al. (2016), and others. Wichink Kruit et al. (2010) followed a unique approach by simplifying complex dynamic approaches towards an empirical steady-state formulation of a non-stomatal compensation-point model, which is used today within the DEPAC3.11 deposition module (van Zanten et al., 2010), the chemistry transport model LOTOS-EUROS (Wichink Kruit et al., 2012), and is structurally compatible with the Massad et al. (2010) model. We highlight strengths and weaknesses of both approaches and apply them to five measurement sites in Germany, the UK, the Netherlands, and Switzerland. Predicted (effective) non-stomatal resistances are compared to those inferred from night-time flux measurements, when stomata are mostly closed and the contribution of the non-stomatal pathway to the total observed flux is dominant. In addition, we investigate the potential of parameterizing a bidirectional non-stomatal exchange model by testing backwards-looking moving averages of air ammonia concentrations as a proxy for prior ammonia inputs into the ecosystem. This eliminates the need for dynamic or iterative flux-based approaches with the use of a readily available, easy-to-calculate and easy-toimplement metric.

\section{Methods}

\subsection{Bidirectional ammonia exchange models}

Ammonia dry deposition is typically modeled using an electrical analogy based on a network of serial and parallel resistances. The two-layer model structure introduced by Nemitz et al. (2001) has been recognized as a good compromise between model complexity, ease of use, and accuracy of the resulting exchange fluxes (Flechard et al., 2013), and it is the foundation for the parameterization of Massad et al. (2010) that is used throughout this study. However, in the Massad et al. (2010) formulation the second (soil/leaf-litter) layer is essentially switched off for semi-natural ecosystems and managed ecosystems outside of management events because soil emissions are expected to be negligible in these cases. We therefore focus on the one-layer big-leaf model (Fig. 1) in this paper. For a list of variables used throughout this article, refer to Table S1 in the Supplement.

In the simplest form, the canopy resistance model (e.g., Wesely, 1989; Erisman and Wyers, 1993), surfaceatmosphere fluxes are limited by three resistances in series: The aerodynamic resistance $R_{\mathrm{a}}\{z-d\}\left(\mathrm{s} \mathrm{m}^{-1}\right)$ at the reference height $z-d(\mathrm{~m})$ (where $z(\mathrm{~m})$ is the measurement height above ground and $d(\mathrm{~m})$ is the zero-plane displacement height), the quasi-laminar boundary layer resistance 


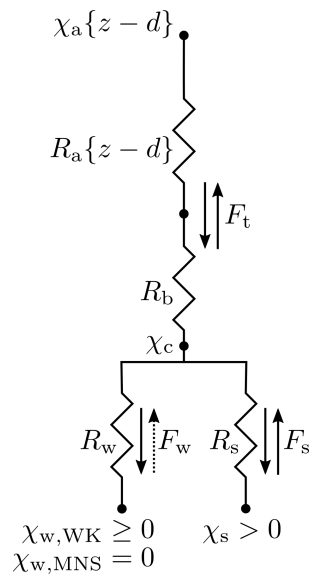

Figure 1. Structure of the single-layer model of $\mathrm{NH}_{3}$ surfaceatmosphere exchange used in this study. The non-stomatal pathway can be treated either uni- or bidirectionally, depending on the specific parameterization. MNS = Massad et al. (2010); WK $=$ Wichink Kruit et al. (2010).

$R_{\mathrm{b}}\left(\mathrm{s} \mathrm{m}^{-1}\right)$, and the canopy resistance $R_{\mathrm{c}}\left(\mathrm{s} \mathrm{m}^{-1}\right)$. While $R_{\mathrm{a}}\{z-d\}$ and $R_{\mathrm{b}}$ are mainly dependent on micrometeorological conditions, surface roughness, and chemical properties of the compound of interest, $R_{\mathrm{c}}$ is directly dependent on the characteristics of the vegetated surface. The inverse of the sum of these three resistances is called the deposition velocity, $v_{\mathrm{d}}\{z-d\}\left(\mathrm{m} \mathrm{s}^{-1}\right)$.

$R_{\mathrm{c}}$ is further split into a stomatal pathway with the stomatal resistance $R_{\mathrm{S}}\left(\mathrm{s} \mathrm{m}^{-1}\right.$ ), and a non-stomatal (or cuticular) pathway with the non-stomatal resistance $R_{\mathrm{w}}\left(\mathrm{s} \mathrm{m}^{-1}\right)$ (e.g., Erisman et al., 1994; Sutton et al., 1998). Stomatal exchange is usually modeled bidirectionally for ammonia in field scale studies and some CTMs, i.e., it is assumed that there is a non-zero gaseous ammonia concentration $\chi_{\mathrm{s}}\left(\mu \mathrm{g} \mathrm{m}^{-3}\right)$ in equilibrium with dissolved ammonia in the apoplastic fluid. This concentration is often called the stomatal compensation point, although strictly speaking the compensation point is only met when $\chi_{\mathrm{s}}$ is approximately equal to the air ammonia concentration at the reference height $\chi_{\mathrm{a}}\{z-d\}\left(\mu \mathrm{g} \mathrm{m}^{-3}\right)$ and consequently the net flux $F_{\mathrm{t}}\left(\mu \mathrm{g} \mathrm{m}^{-2} \mathrm{~s}^{-1}\right)$ is zero (Farquhar et al., 1980). The nonstomatal pathway is modeled unidirectionally in many parameterizations, i.e., the gaseous ammonia concentration in equilibrium with the solution on the external leaf surfaces $\chi_{w}$ $\left(\mu \mathrm{g} \mathrm{m}^{-3}\right)$ is assumed to be zero, although observational evidence indicates that this pathway is in fact bidirectional as well (e.g., Neirynck and Ceulemans, 2008). A canopy compensation point, $\chi_{\mathrm{c}}\left(\mu \mathrm{g} \mathrm{m}^{-3}\right)$, that integrates these two pathways can be calculated as (e.g., Sutton et al., 1995; modified to include $\chi_{\mathrm{w}}$ )

$\chi_{\mathrm{c}}=\frac{\chi_{\mathrm{a}}\{z-d\} \cdot\left(R_{\mathrm{a}}+R_{\mathrm{b}}\right)^{-1}+\chi_{\mathrm{s}} \cdot R_{\mathrm{s}}^{-1}+\chi_{\mathrm{w}} \cdot R_{\mathrm{w}}^{-1}}{\left(R_{\mathrm{a}}\{z-d\}+R_{\mathrm{b}}\right)^{-1}+R_{\mathrm{s}}^{-1}+R_{\mathrm{w}}^{-1}}$, and the total net flux of ammonia to or from the ecosystem, $F_{\mathrm{t}}\left(\mu \mathrm{g} \mathrm{m}^{-2} \mathrm{~s}^{-1}\right)$ as

$F_{\mathrm{t}}=-\frac{\chi_{\mathrm{a}}\{z-d\}-\chi_{\mathrm{c}}}{R_{\mathrm{a}}\{z-d\}+R_{\mathrm{b}}}$,

where by convention negative fluxes indicate deposition towards the surface and positive fluxes indicate emission. This is typically done on a half-hour basis for consistency with flux measurement practices. $R_{\mathrm{a}}\{z-d\}$ and $R_{\mathrm{b}}$ are here modeled after Garland (1977) as

$R_{\mathrm{a}}\{z-d\}=\frac{u\{z-d\}}{u_{*}^{2}}-\frac{\Psi_{\mathrm{H}}\left\{\frac{z-d}{L}\right\}-\Psi_{\mathrm{M}}\left\{\frac{z-d}{L}\right\}}{k \cdot u_{*}}$,

and

$R_{\mathrm{b}}=u_{*}^{-1}\left[1.45 \cdot\left(\frac{z_{0 \cdot u_{*}}}{v_{\text {air }}}\right)^{0.24} \cdot\left(\frac{v_{\text {air }}}{D_{\mathrm{NH}_{3}}}\right)^{0.8}\right]$,

where $u\{z-d\}\left(\mathrm{m} \mathrm{s}^{-1}\right)$ is the wind speed at the reference height, $u_{*}\left(\mathrm{~m} \mathrm{~s}^{-1}\right)$ is the friction velocity, $L(\mathrm{~m})$ is the Obukhov length, $k(-)$ is the von Kármán constant $(k=$ $0.41), \Psi_{\mathrm{H}}(-)$ and $\Psi_{\mathrm{M}}(-)$ are the integrated stability corrections for entrained scalars and momentum, respectively, after Webb (1970) and Paulson (1970), $z_{0}(\mathrm{~m})$ is the roughness length, $v_{\text {air }}\left(\mathrm{m}^{2} \mathrm{~s}^{-1}\right)$ is the kinematic viscosity of air, and $D_{\mathrm{NH}_{3}}\left(\mathrm{~m}^{2} \mathrm{~s}^{-1}\right)$ is the molecular diffusivity of ammonia in air. $R_{\mathrm{S}}$ can be modeled using at least a light and temperature response function (e.g., Wesely, 1989), often with additional reduction factors accounting for vapor pressure deficit, soil moisture, and other environmental variables (e.g., Emberson et al., 2000). However, this study focuses on nighttime fluxes when non-stomatal fluxes are assumed to be dominant. If $R_{\mathrm{S}}$ is assumed to approach infinity at nighttime, all terms involving $R_{\mathrm{s}}$ in Eq. (1) collapse to zero.

\subsection{Most recent non-stomatal resistance parameterizations}

\subsubsection{Massad et al. (2010)}

Based on an extensive meta-analysis, Massad et al. (2010) derived a parameterization (henceforth referred to as $M N S$ ) for a unidirectional non-stomatal pathway model (i.e., $\left.\chi_{\mathrm{w}}=0\right)$ that models the effect of the air pollution climate by incorporating a so-called acid ratio, AR (-), to scale the minimum allowed $R_{\mathrm{w}}$. It is defined as the molar ratio of average total acid $/ \mathrm{NH}_{3}$ concentrations, $\mathrm{AR}=\left(2\left[\mathrm{SO}_{2}\right]+\left[\mathrm{HNO}_{3}\right]+[\mathrm{HCl}]\right) /\left[\mathrm{NH}_{3}\right]$, and is an extension of the classical $\left[\mathrm{SO}_{2}\right] /\left[\mathrm{NH}_{3}\right]$ co-deposition proxy concept following the decline of $\mathrm{SO}_{2}$ emissions in Europe during the last few decades (e.g., Erisman et al., 2001). In addition, effects of leaf area index LAI $\left(\mathrm{m}^{2} \mathrm{~m}^{-2}\right)$ and temperature $T$ $\left({ }^{\circ} \mathrm{C}\right)$ are modeled following Zhang et al. (2003) and Flechard et al. (2010), respectively. With all corrections $R_{\mathrm{W}}$ is given as

$R_{\mathrm{w}, \mathrm{MNS}}=R_{\mathrm{w}, \min } \cdot \mathrm{AR}^{-1} \cdot e^{a \cdot(100-\mathrm{RH})} \cdot \frac{e^{\beta \cdot|T|}}{\sqrt{ } \mathrm{LAI}}$, 
where $R_{\mathrm{w}, \min }=31.5 \mathrm{~s} \mathrm{~m}^{-1}$ is the "baseline" minimum $R_{\mathrm{w}}$, $a(-)$ is an empirical ecosystem-specific parameter ranging from $0.0318 \pm 0.0179$ for forests to $0.176 \pm 0.126$ for grasslands, $\mathrm{RH}(\%)$ is relative humidity, LAI $\left(\mathrm{m}^{2} \mathrm{~m}^{-2}\right)$ is onesided leaf area index, $\beta=0.15^{\circ} \mathrm{C}^{-1}$ is a temperature response parameter, and $T\left({ }^{\circ} \mathrm{C}\right)$ is the temperature. The exponential decay parameter $a$ was calculated as an average of $a$ values per land-use class reported in the literature (Massad et al., 2010). Note that the temperature response was originally derived using temperatures scaled to the notional height of trace gas exchange $z_{0}^{\prime}(\mathrm{m})$. Since sensible heat flux measurements, which are required for this extrapolation (e.g., Nemitz et al., 2009), were not available for all sites, we here used measured air temperatures instead. The influence of using $T$ and $\mathrm{RH}$ at the reference height instead of $z_{0}^{\prime}$ is discussed later in this paper. Contrary to the original formulation of Flechard et al. (2010), Massad et al. (2010) do not use absolute values of $|T|\left({ }^{\circ} \mathrm{C}\right)$, but we chose to do so under the assumption that generally $R_{\mathrm{W}}$ increases in freezing conditions (e.g., Erisman and Wyers, 1993).

\subsubsection{Wichink Kruit et al. (2010)}

Following the bidirectional non-stomatal exchange paradigm introduced in the cuticular capacitance model of Sutton et al. (1998), Wichink Kruit et al. (2010) developed a simplified steady-state non-stomatal compensation point $\left(\chi_{\mathrm{w}}\right)$ model (henceforth referred to as $W K$ ) using three years of flux measurements over an unfertilized grassland in the Netherlands. In this model, a simple exponential humidity response after Sutton and Fowler (1993) is used as an approximation for $R_{\mathrm{W}}$ under low ambient $\mathrm{NH}_{3}$ concentrations, where saturation of the external leaf surfaces is unlikely (Wichink Kruit et al., 2010; Milford et al., 2001):

$R_{\mathrm{w}, \mathrm{WK}}=2 \cdot e^{\frac{1}{12} \cdot(100-\mathrm{RH})}$.

$\chi_{\mathrm{w}}\left(\mu \mathrm{g} \mathrm{m}^{-3}\right)$ is calculated from the temperature response of the Henry equilibrium and the ammonium-ammonia dissociation equilibrium, similar to formulations used for the stomatal compensation point (e.g., Nemitz et al., 2000), as

$\chi_{\mathrm{w}}=\frac{2.75 \times 10^{15}}{T+273.15} \cdot e^{\left(-\frac{1.04 \times 10^{4}}{T+273.15}\right)} \cdot \Gamma_{\mathrm{w}}$,

where $\Gamma_{\mathrm{w}}(-)$ is the non-stomatal emission potential and corresponds to the molar ratio of $\left[\mathrm{NH}_{4}^{+}\right]$to $\left[\mathrm{H}^{+}\right]$in the leaf surface water layers. Wichink Kruit et al. (2010) derived a functional relationship for $\Gamma_{\mathrm{w}}$ from measurements of the ammonia air concentration at a reference height of $4 \mathrm{~m}$ :

$\Gamma_{\mathrm{w}}=1.84 \times 10^{3} \cdot \chi_{\mathrm{a}}\{4 \mathrm{~m}\} \cdot e^{-0.11 \cdot T}-850$.

The WK model is only structurally bidirectional in that the effect of the air pollution climate is shifted from $R_{\mathrm{W}}$ to $\chi_{\mathrm{w}}$. In practice, as $\chi_{\mathrm{w}}$ is parameterized as a fraction of $\chi_{\mathrm{a}}$, no emissions can occur (cf. van Zanten et al., 2010, Appendix F).
An effective non-stomatal resistance, $R_{\mathrm{w}, \text { eff. }}\left(\mathrm{s} \mathrm{m}^{-1}\right)$, that produces identical results when used with a unidirectional non-stomatal resistance-only model, can be written as

$R_{\mathrm{w}, \text { eff. }}=\frac{\chi_{\mathrm{c}} \cdot R_{\mathrm{w}}}{\chi_{\mathrm{c}}-\chi_{\mathrm{w}}}$

or during nighttime conditions, when $R_{\mathrm{S}}$ is here assumed to approach infinity, as

$$
\begin{aligned}
& R_{\mathrm{W}, \text { eff.,nighttime }}= \\
& \frac{\chi_{\mathrm{a}}\{z-d\} \cdot R_{\mathrm{W}}+\chi_{\mathrm{w}} \cdot\left(R_{\mathrm{a}}\{z-d\}+R_{\mathrm{b}}\right)}{\chi_{\mathrm{a}}\{z-d\}-\chi_{\mathrm{w}}} .
\end{aligned}
$$

Note that Wichink Kruit et al. (2010) used surface temperatures estimated from outgoing long wave radiation and the Stefan-Boltzmann law, but in practice the model is routinely run with air temperatures within the DEPAC3.11 code (van Zanten et al., 2010). As with the MNS model, the difference between using air and surface temperatures when the latter was available was investigated in a small sensitivity study.

\subsection{Theoretical considerations and generation of hypotheses}

The MNS model uses a minimum non-stomatal resistance $R_{\mathrm{w}, \min }$ of $31.5 \mathrm{~s} \mathrm{~m}^{-1}$, which is further significantly increased when $\mathrm{AR}<1, \mathrm{RH}<100 \%$, LAI $<1$, and $T \neq 0{ }^{\circ} \mathrm{C}$ (Fig. 2). For example, at $\mathrm{AR}=0.5$ and $T=10^{\circ} \mathrm{C}$, the minimum allowed $R_{\mathrm{w}}$ at $100 \%$ relative humidity lies between 163 and $282 \mathrm{~s} \mathrm{~m}^{-1}$ for an LAI range of 1 to $3 \mathrm{~m}^{2} \mathrm{~m}^{-2}$. It is evident from Table 1 of Massad et al. (2010) that $\mathrm{AR}<1$ is no rare occurrence, but compared to minimum measured $R_{\mathrm{W}}$ (ibid.) predicted values appear to be rather high. It should also be noted that in the MNS model, the deposition velocity can never reach the maximum limit allowed by turbulence $v_{\mathrm{d}, \max }\{z-d\}\left(\mathrm{m} \mathrm{s}^{-1}\right)$ :

$v_{\mathrm{d}, \max }\{z-d\}=\left(R_{\mathrm{a}}\{z-d\}+R_{\mathrm{b}}\right)^{-1}$.

The temperature-dependent parameterization of $\Gamma_{\mathrm{w}}$ in the WK model can lead to contrasting effects: When temperatures increase, the exponential decay function in Eq. (8) can completely counter the growth of Eq. (7). In other words, depending on $\mathrm{NH}_{3}$ air concentration levels, after a certain cutoff temperature the non-stomatal compensation point $\chi_{\mathrm{w}}$ decreases (Fig. 2), although with a constant $\Gamma_{\mathrm{w}}$ an equilibrium shift towards gaseous ammonia would be expected to lead to a further exponential increase of $\chi_{\mathrm{w}}$. Consequently, when $T$ is high and $\chi_{\mathrm{w}}$ approaches zero, $\chi_{\mathrm{c}}$ is canceled out in Eq. (9) and $R_{\mathrm{w}, \text { eff. }}$ becomes equal to the clean air $R_{\mathrm{w}, \mathrm{WK}}$ (Eq. 6), which at $100 \%$ relative humidity is as low as $2 \mathrm{~s} \mathrm{~m}^{-1}$.

Based on these considerations, we hypothesize that

i. The MNS model has a tendency to overestimate $R_{\mathrm{W}}$ and consequently to underestimate $F_{\mathrm{t}}$, especially at sites with low acid ratios. 

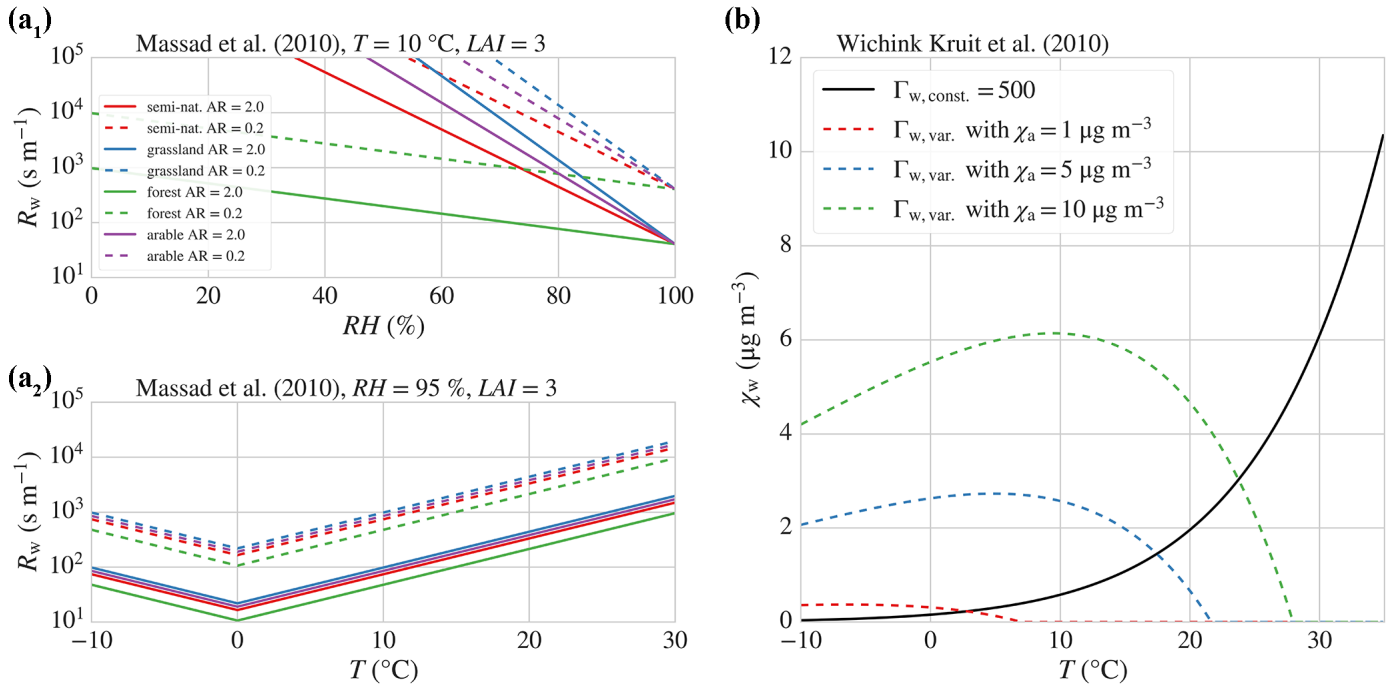

Figure 2. Theoretical considerations about the non-stomatal resistance parameterizations' response to changes in micrometeorological conditions. (a) Non-stomatal resistance $\left(R_{\mathrm{W}}\right)$ as a function of $\left(\mathbf{a}_{1}\right)$ relative humidity $(\mathrm{RH})$ and $\left(\mathbf{a}_{2}\right)$ temperature $(T)$ for different ecosystems and pollution climates according to the Massad et al. (2010) parameterization. (b) Non-stomatal compensation point ( $\left.\chi_{\mathrm{w}}\right)$ as a function of air ammonia concentration $\left(\chi_{\mathrm{a}}\right)$ and temperature $(T)$ in the Wichink Kruit et al. (2010) parameterization.

Table 1. Summary of the five datasets. AGM = aerodynamic gradient method; EC= eddy covariance, MNS = Massad et al. (2010). Measurement period is the period during which flux measurements were available after final data filtering. $T$ and $\chi_{\mathrm{a}}$ ranges are minimum and maximum values during the measurement period and values in parentheses denote the 5, 50, and $95 \%$ quantiles.

\begin{tabular}{|c|c|c|c|c|c|c|c|c|}
\hline ID & Site name & $\begin{array}{l}\text { Ecosystem type } \\
\text { in MNS }\end{array}$ & $\begin{array}{l}\text { Measurement } \\
\text { period mm/yyyy }\end{array}$ & $\begin{array}{l}\text { Measurement } \\
\text { technique }\end{array}$ & $T\left({ }^{\circ} \mathrm{C}\right)$ & $\chi_{\mathrm{a}}\left(\mu \mathrm{g} \mathrm{m}^{-3}\right)$ & avg. AR (-) & Reference \\
\hline AM & $\begin{array}{l}\text { Auchencorth } \\
\text { Moss (UK) }\end{array}$ & semi-natural & $\begin{array}{l}02 / 1995-02 / 1996 \\
05 / 1998-11 / 1998\end{array}$ & AGM & $\begin{array}{r}-7.8-26.9 \\
(0.0,9.4,17.3)\end{array}$ & $\begin{array}{r}0.0-32.9 \\
(0.1,0.4,2.9)\end{array}$ & 0.7 & $\begin{array}{l}\text { Flechard et } \\
\text { al. (1999) }\end{array}$ \\
\hline $\mathrm{BM}$ & $\begin{array}{l}\text { Bourtanger } \\
\text { Moor (DE) }\end{array}$ & semi-natural & $02 / 2014-05 / 2014$ & $\mathrm{EC}$ & $\begin{array}{r}-4.4-22.3 \\
(0.7,7.3,17.8)\end{array}$ & $\begin{array}{r}1.6-62.0 \\
(3.2,9.0,26.6)\end{array}$ & 0.1 & $\begin{array}{l}\text { Zöll et } \\
\text { al. (2016) }\end{array}$ \\
\hline $\mathrm{OE}$ & $\begin{array}{l}\text { Oensingen } \\
(\mathrm{CH})\end{array}$ & grassland & 07/2006-10/2007 & AGM & $\begin{array}{r}-3.0-33.1 \\
(1.2,12.3,23.8)\end{array}$ & $\begin{array}{r}0.0-24.7 \\
(0.4,2.2,8.0)\end{array}$ & 0.4 & $\begin{array}{l}\text { Spirig et } \\
\text { al. (2010) }\end{array}$ \\
\hline SV & $\begin{array}{l}\text { Solleveld } \\
\text { (NL) }\end{array}$ & grassland & 09/2014-08/2015 & AGM & $\begin{array}{r}-1.5-31.7 \\
(3.4,11.6,20.4)\end{array}$ & $\begin{array}{r}0.1-15.6 \\
(0.2,1.2,6.6)\end{array}$ & 0.5 & unpublished \\
\hline VK & $\begin{array}{l}\text { Veenkampen } \\
\text { (NL) }\end{array}$ & grassland & 01/2012-10/2013 & AGM & $\begin{array}{r}-5.4-31.6 \\
(4.0,15.2,26.2)\end{array}$ & $\begin{array}{r}0.3-116.9 \\
(2.5,8.8,27.7)\end{array}$ & 0.3 & unpublished \\
\hline
\end{tabular}

ii. The WK model has a tendency to underestimate $R_{\mathrm{w}}$ and consequently to overestimate $F_{\mathrm{t}}$, especially during high temperatures and low air ammonia concentrations.

\subsection{Derivation of nighttime non-stomatal resistances from flux measurements}

Non-stomatal resistance models are parameterized using flux measurements during reasonably turbulent, i.e., near-neutral or only slightly stable, nighttime conditions. When stomatal closure is high and therefore $R_{\mathrm{S}} \gg R_{\mathrm{w}}$, we can assume that the canopy resistance $R_{\mathrm{c}}$ is approximately equal to $R_{\mathrm{W}}$ based on the single-layer model when the non-stomatal pathway is treated unidirectional:

$R_{\mathrm{w}, \mathrm{obs} .} \approx-\frac{\chi_{\mathrm{a}}\{z-d\}}{F_{\mathrm{t}}}-\left(R_{\mathrm{a}}\{z-d\}+R_{\mathrm{b}}\right)$ where $R_{\mathrm{w}, \mathrm{obs}}\left(\mathrm{s} \mathrm{m}^{-1}\right)$ is the observed non-stomatal resistance, and $F_{\mathrm{t}}$ is in $\mu \mathrm{g} \mathrm{m}^{-2} \mathrm{~s}^{-1} . R_{\mathrm{w}, \text { obs. values were selected }}$ from turbulent nighttime conditions (e.g., Wichink Kruit et al., 2010), when $R_{\mathrm{a}}\{z-d\}+R_{\mathrm{b}}<200 \mathrm{~s} \mathrm{~m}^{-1}, u_{*}>0.1 \mathrm{~m} \mathrm{~s}^{-1}$, and global radiation $<10 \mathrm{~W} \mathrm{~m}^{-2}$.

Existing datasets of flux measurements were used for a comparison of measured and modeled $R_{\mathrm{w}}$. These measurements were conducted at two peatland sites, Auchencorth Moss (AM) in the United Kingdom, and Bourtanger Moor (BM) in Germany, as well as three grassland sites, Oensingen (OE) in Switzerland, and Solleveld (SV) and Veenkampen (VK), in the Netherlands. At AM, OE, SV, and VK, the aerodynamic gradient method was used and at BM the eddy covariance method was used. For detailed site and measurement setup descriptions, the reader is referred to Flechard et al. (1999) for AM, Zöll et al. (2016) and Hurkuck et 

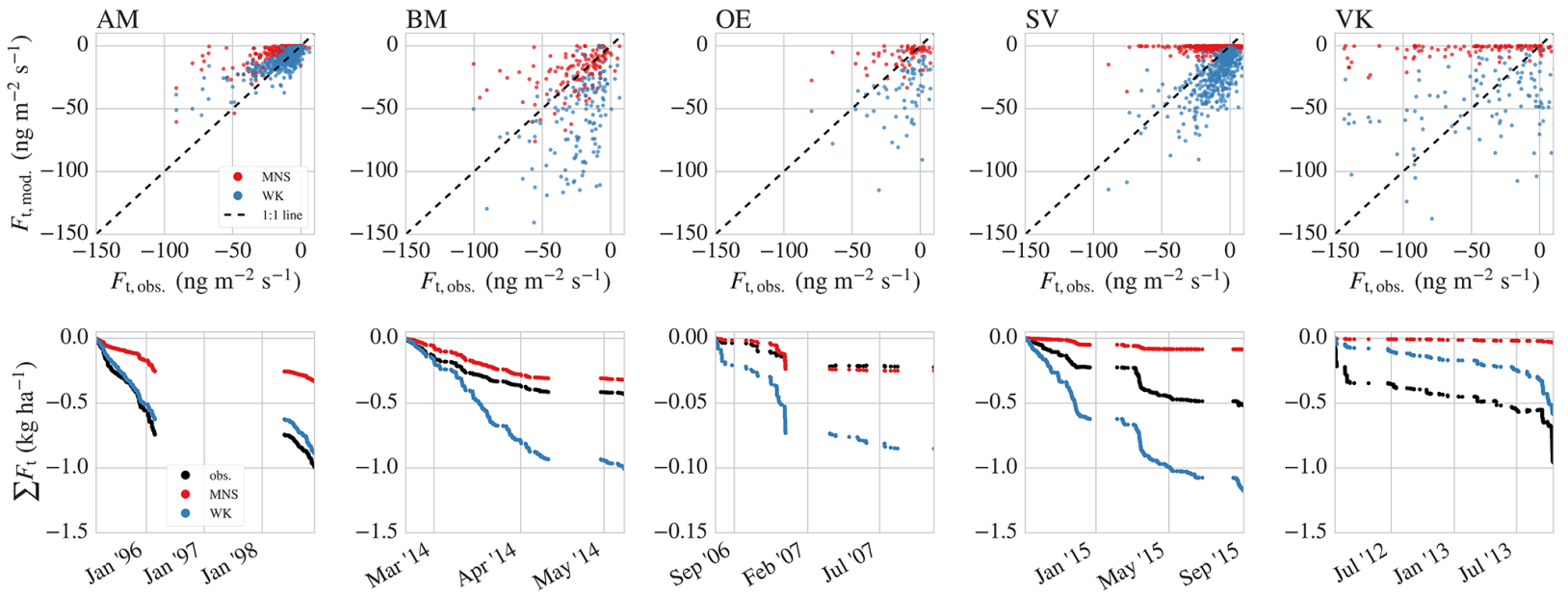

Figure 3. Measured and modeled ammonia dry deposition fluxes $\left(F_{\mathrm{t}}\right)$ during near-neutral or slightly stable nighttime conditions. (Upper row) Modeled vs. measured $6 \mathrm{~h}$ median flux densities. (Lower row) Cumulative fluxes. obs. $=$ observations; MNS $=$ Massad et al. (2010); $\mathrm{WK}=$ Wichink Kruit et al. (2010). Refer to the text for site descriptors. Note the different scaling of the axes.

al. (2014) for BM, and Spirig et al. (2010) for OE. SV and VK datasets are unpublished as of now. SV is best characterized as a semi-natural grassland and is located in the dune area west of The Hague, $\mathrm{NL}$. $\mathrm{NH}_{3}$ concentration profiles were measured using a Gradient Ammonia High Accuracy Monitor (GRAHAM; Wichink Kruit et al., 2007) system with inlets at $0.8,1.7$, and $3.6 \mathrm{~m}$ above ground. $\mathrm{VK}$ is an experimental grassland site used by Wageningen UR for meteorological measurements, where $\mathrm{NH}_{3}$ was sampled at 0.8 and $2.45 \mathrm{~m}$ above ground using differential optical absorption spectroscopy (DOAS; Volten et al., 2012). A brief overview of measurement conditions at the five sites is given in Table 1. LAI and canopy height $h_{\mathrm{c}}(\mathrm{m})$ measurements were available for $\mathrm{AM}$ and $\mathrm{OE}$, and the default values proposed in Table 6 of Massad et al. (2010) were used at the other sites. Emission events at OE not suitable for this study were filtered out by removing 9 days of measurements after a fertilization event, based on the $e$-folding time of 2.88 days used for fertilizer emission potentials in Massad et al. (2010), which translates into a $95 \%$ "extinction time" of 8.63 days for the management influence. For VK, no management logs for the measurement site or the surrounding fields were available and only two strong emission periods were removed manually after visual inspection of the dataset.

\subsection{Proposal for a semi-dynamic parameterization of non-stomatal emission potentials}

The Wichink Kruit et al. (2010) parameterization was developed for frameworks within which the use of dynamic cuticular capacitance models in conjunction with leaf surface chemistry modules may not be practical (e.g., to limit computation time of large scale CTMs). While it is capable of modeling saturation effects with an ambient ammonia concentration-dependent non-stomatal compensation point, it only relies on $\chi_{\mathrm{a}}$ at the current calculation step. A compromise between the truly dynamic models of Sutton et al. (1998) and Flechard et al. (1999) and the steady-state simplification of Wichink Kruit et al. (2010) would respect the site's history of reactive nitrogen inputs without falling back to a numerically dynamic model and, consequently, the same difficulties that limit the application of existing dynamic approaches in large-scale models, i.e., it would need to use a proxy for previous nitrogen deposition without relying on the model's flux predictions at an earlier calculation time. Here we additionally investigate the feasibility of a $\Gamma_{\mathrm{w}}$ parameterization based on backward-looking moving averages of air ammonia concentrations as a proxy for prior $\mathrm{NH}_{3}$ inputs into the system, which might saturate leaf water layers and enhance the compensation points. If such a relationship exists, it can provide an easy-to-use metric that can be calculated from readily available observations without the need for spinning up and iteratively solving a model for $F_{\mathrm{t}}$ estimates, while still allowing the use of a more mechanistic bidirectional approach to non-stomatal exchange. $\Gamma_{\mathrm{w}}$ values are derived as done by Wichink Kruit et al. (2010), i.e., $R_{\mathrm{W}}$ is parameterized for clean air according to Eq. (6), $\chi_{\mathrm{w}}$ is calculated as

$\chi_{\mathrm{w}}=\chi_{\mathrm{a}}\{z-d\}+F_{\mathrm{t}} \cdot\left(R_{\mathrm{a}}\{z-d\}+R_{\mathrm{b}}+R_{\mathrm{w}, \mathrm{WK}}\right)$,

and finally, $\Gamma_{\mathrm{w}}$ is calculated by rearranging Eq. (7) to

$\Gamma_{\mathrm{w}}=\frac{T+273.15}{2.75 \times 10^{15}} \cdot e^{\left(\frac{1.04 \times 10^{4}}{T+273.15}\right)} \cdot \chi_{\mathrm{w}}$.

The relationship was investigated for moving-windows of different lengths $(1,3,7$, and 14 days) under exclusion of periods with substantial rainfall $\left(>5 \mathrm{~mm} \mathrm{day}^{-1}\right)$. 

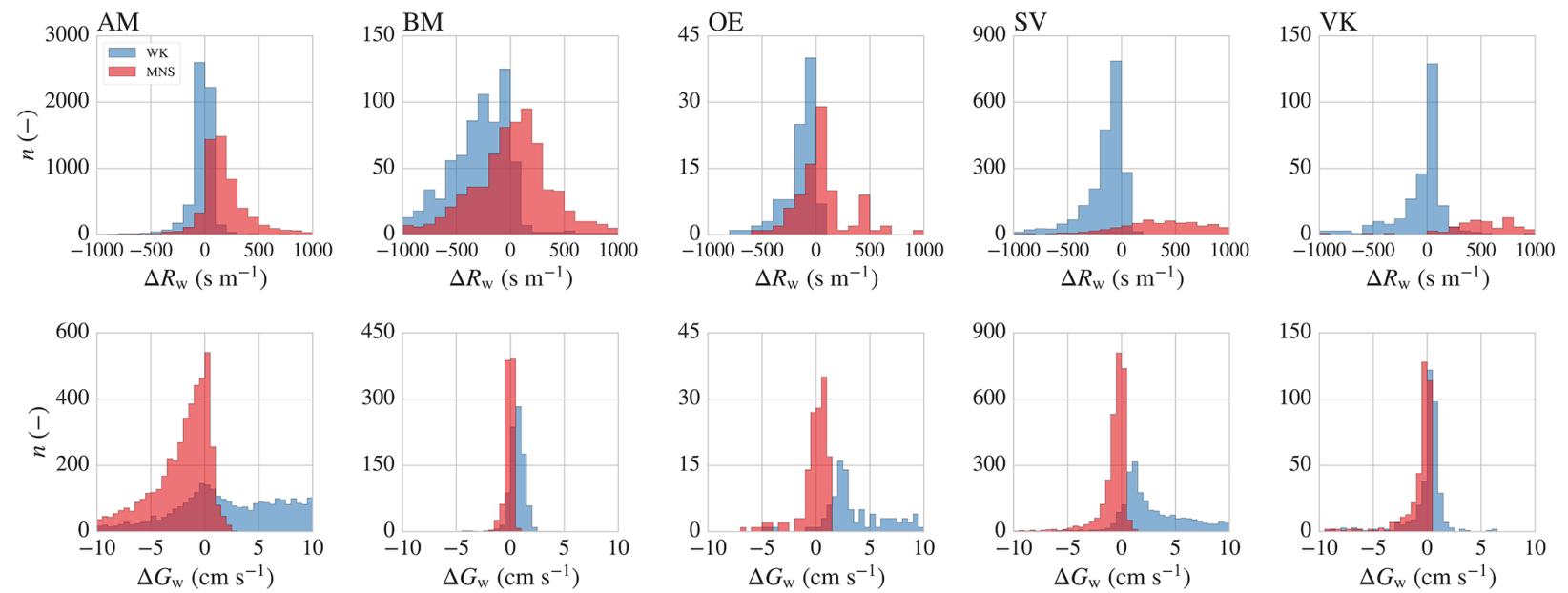

Figure 4. Differences in measured and modeled 30 min nighttime non-stomatal resistances $\left(R_{\mathrm{W}}\right.$, upper row, $100 \mathrm{~s} \mathrm{~m}^{-1}$ bins) and conductances ( $G_{\mathrm{W}}$, lower row, $0.5 \mathrm{~cm} \mathrm{~s}^{-1}$ bins). $\Delta R_{\mathrm{W}}=R_{\mathrm{W} \text {, modeled }}-R_{\mathrm{W} \text {,observed }}$ and $\Delta G_{\mathrm{W}}=G_{\mathrm{W} \text {,modeled }}-G_{\mathrm{W}, \text { observed }}$, i.e., positive values indicate an overestimation and negative values indicate an underestimation by the models. Note that an overestimation of $R_{\mathrm{W}}$ leads to an underestimation of fluxes $F_{\mathrm{t}}$, whereas an overestimation of $G_{\mathrm{W}}$ leads to an overestimation of $F_{\mathrm{t}}$.

\section{Results and discussion}

\subsection{Comparison of existing parameterizations with observations}

The MNS model tends to underestimate nighttime $F_{\mathrm{t}}$ at all five sites, whereas the WK model overestimates $F_{\mathrm{t}}$ for BM, $\mathrm{OE}$, and $\mathrm{SV}$, underestimates it for $\mathrm{VK}$, and only very slightly underestimates it for AM (Fig. 3). Note that total cumulative $F_{\mathrm{t}}$ in Fig. 3 is by no means representative for an estimate for total $\mathrm{NH}_{3}$ input during these times, but based on non-gap filled nighttime fluxes only. Additionally, a mismatch between modeled and measured flux densities early in the time series propagates through the whole time series of cumulative fluxes. For example, at BM the MNS model performs very well after a mismatch during the first week, whereas the WK model fits the observations closely until mid-March 2014. Similarly, the strong deposition event early in the VK time series is not reproduced by either of the models. Comparing differences in modeled and measured nighttime $R_{\mathrm{w}}$ (Fig. 4, upper row) supports these observations: while using the MNS model leads to an overestimation of the majority of observed $R_{\mathrm{W}}$ at all sites, as hypothesized, the picture is not as clear for WK. Here, the majority of modeled $R_{\mathrm{W}}$ values lie below the observations for $\mathrm{BM}, \mathrm{OE}, \mathrm{SV}$, and VK; however, for AM and VK both frequent over- and underestimations of $R_{\mathrm{w}}$ canceled each other out, thereby leading to fairly reasonable predicted net fluxes at these two sites. The inverse of these resistances, the non-stomatal conductance $G_{\mathrm{w}}=R_{\mathrm{w}}^{-1}$, may be a better predictor for the resulting fluxes, as very high resistances have a negligible effect on fluxes. Differences between modeled and measured $G_{\mathrm{w}}$ are shown in the lower row of Fig. 4 and generally lead to similar conclusions (note that here underestimations of $G_{\mathrm{w}}$ directly lead to underestimations of $F_{\mathrm{t}}$ ), but emphasize the relatively good predictive capabilities of MNS at BM and WK at VK during most times, which may not immediately be obvious from looking at cumulative fluxes (Fig. 3).

We attribute the mismatch of the MNS model results and measurements to the relatively high baseline minimum allowed $R_{\mathrm{w}}$ and the strong response of the temperature correction function (Fig. 5, left panel). Note that AR at all sites is lower than 1, ranging from 0.1 at $\mathrm{BM}$ to 0.7 at $\mathrm{AM}$, which results in minimum $R_{\mathrm{w}}$ of 315 and $45 \mathrm{~s} \mathrm{~m}^{-1}$ before LAI and $T$ correction, respectively. For example, at $\mathrm{OE}$ with an AR of 0.4 and an average LAI of approximately $2 \mathrm{~m}^{2} \mathrm{~m}^{-2}$, even under conditions highly favoring deposition towards the external leaf surface in the MNS model $(\mathrm{RH}=100 \%$, $T=0{ }^{\circ} \mathrm{C}$ ), deposition velocity is restricted to an upper bound of $1.8 \mathrm{~cm} \mathrm{~s}^{-1}$, although observations regularly exceeded this threshold. In their comprehensive literature review, Massad et al. (2010) themselves report $R_{\mathrm{w}, \mathrm{min}}$ between 1 and $30 \mathrm{~s} \mathrm{~m}^{-1}$ for grassland and between 0.5 and $24 \mathrm{~s} \mathrm{~m}^{-1}$ for semi-natural ecosystems. In contrast, in their parameterization of $R_{\mathrm{w}}$ the actual deposition velocity can never approach the theoretical limit allowed by turbulence (Eq. 11), although this case was regularly observed in the field. This is of course true for all unidirectional $R_{\mathrm{W}}$ parameterizations of the commonly used $R_{\mathrm{W}}=R_{\mathrm{w}, \min } \cdot e^{a \cdot(100-\mathrm{RH})}$ form; however, in the WK model a small minimum $R_{\mathrm{W}}$ of $2 \mathrm{~s} \mathrm{~m}^{-1}$ allows $v_{\mathrm{d}}\{z-d\}$ to approach $v_{\mathrm{d}, \max }\{z-d\}$ closely. Regarding the temperature correction, the parameter $\beta=0.15^{\circ} \mathrm{C}^{-1}$ translates into an increase of $R_{\mathrm{W}}$ by a factor of 4.5 with a $T$ increase of $10 \mathrm{~K}$. Equation (7), however, only predicts an increase of the compensation point $\chi_{\mathrm{w}}$ by a factor of approximately 2.8 to 4.1 for a $T$ increase of $10 \mathrm{~K}$, depending on the starting temper- 

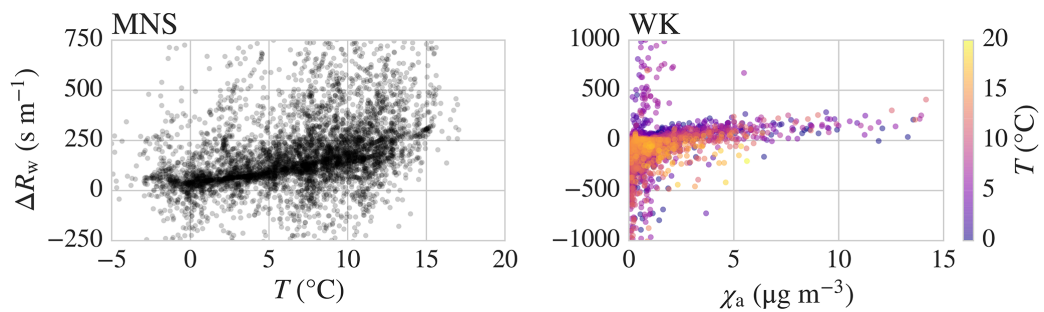

Figure 5. Differences between modeled and measured 30 min nighttime non-stomatal resistances $\left(\Delta R_{\mathrm{W}}\right)$ as a function of $T$ and/or $\chi_{\mathrm{a}}$. (Left panel) Increasing mismatch of measured and modeled $R_{\mathbf{W}}$ in the MNS model due to a too strong $T$ response. The line-shaped pattern emerges from times when observed $R_{\mathrm{W}}$ is zero and is equal in magnitude to the minimum allowed $R_{\mathrm{W}}$ in the parameterization. (Right panel) The WK model reveals a tendency for both stronger over- and underestimation of observed $R_{\mathrm{W}}$ with increasing $\chi_{\mathrm{a}}$, where overestimation occurs more frequently during colder conditions and underestimation during warmer conditions.

ature, which translates into a significantly smaller factor for $R_{\mathrm{W}, \text { eff. }}$ considering the influence of other variables in Eqs. (9) and/or (10). Note, the relatively good agreement with measured fluxes at BM, despite the very low AR.

Reasons for strikingly diverse performance of the WK model are not straightforward, but may be explained based on the combined effect of $T$ and $\chi_{\mathrm{a}}$ on the $\Gamma_{\mathrm{w}}$ parameterization, as depicted in Fig. 2. For example, at BM the model performs relatively well until mid-March 2014 (Fig. 3), when measured fluxes decrease, whereas modeled fluxes remain at a similar level and later even increase. This observation corresponds to an increase in both $T$ and $\chi_{\mathrm{a}}$ at the site (cf. Zöll et al., 2016), leading to a decrease in effective $R_{\mathrm{w}}$ and therefore an increase in modeled $F_{\mathrm{t}}$. In fact, with all sites pooled into one combined dataset, two interesting characteristics of the parameterization emerge from a plot of differences in modeled and measured $R_{\mathrm{w}}$ against $\chi_{\mathrm{a}}$ (Fig. 5, right panel): (i) The underestimation of $R_{\mathrm{w}}$ does indeed increase with rising temperatures and $\chi_{\mathrm{a}}$, as hypothesized. (ii) There is an additional tendency to actually overestimate $R_{\mathrm{w}}$ when temperatures are relatively low, which strongly responds to increasing $\chi_{\mathrm{a}}$ and may be an indication of a too high modeled $\Gamma_{\mathrm{w}}$ under these conditions. These two contrasting effects may explain the good agreement of net modeled and measured cumulative fluxes e.g., at AM, where concentrations were relatively low during most times and both low and high temperatures without extremes were measured.

\subsection{Semi-dynamic $\Gamma_{w}$}

Estimated non-stomatal emission potentials $\Gamma_{\mathrm{w}}$ appear to have a strong dependency on backward-looking moving averages of measured air ammonia concentrations $\chi_{\mathrm{a}, \mathrm{MA}}$ $\left(\mu \mathrm{g} \mathrm{m}^{-3}\right)$ (Fig. 6). While this may indicate some potential as an easy-to-use and readily available proxy for prior $\mathrm{NH}_{3}$ inputs without the need for more complex and/or computationally intensive mechanistic models, estimated $\Gamma_{\mathrm{w}}$ values are extremely noisy and span multiple orders of magnitude in the $<5 \mu \mathrm{g} \mathrm{m}^{-3}$ range. An increase in the movingwindow length from 1 day (Fig. 6a) to 14 days (Fig. 6d) does not lead to a substantial decrease in the magnitude of the noise. There is a very clear linear relationship when logtransforming both $\Gamma_{\mathrm{w}}$ and $\chi_{\mathrm{a}, \mathrm{MA}}\left(R^{2}=0.62\right.$ for the 1 day moving average case; not shown); however, the strong variability of the data, especially in the low-concentration region, leads to a best fit that predicts large $\Gamma_{\mathrm{w}}$ even at concentrations as low as $1 \mu \mathrm{g} \mathrm{m}^{-3}\left(\Gamma_{\mathrm{w}} \approx 380\right)$, which eventually ends in unreasonably high emission fluxes. Without further noise reduction, this approach appears unfeasible as an alternative to more sophisticated dynamic models (e.g., Flechard et al., 1999) or those featuring additional dependencies such as the one of Wichink Kruit et al. (2010). Making the movingwindow width dependent on time since the last substantial precipitation event might help reduce this noise and lead to a more realistic representation, but in turn complicates the implementation and increases the degrees of freedom in this approach, thereby reducing its advantage over mechanistically more accurate models.

\subsection{MNS with updated parameters}

Since we hypothesized the reasons for the mismatch between MNS-modeled $R_{\mathrm{w}}$ and measured $R_{\mathrm{w}, \mathrm{obs}}$ to be based on two easily accessible parameters with relatively obvious effects on modeled resistances $\left(R_{\mathrm{w}, \min }\right.$ and the temperature response parameter $\beta$ in Eq. 5), we additionally investigated the effects of adjusting them towards smaller values. Figure 7 shows the effects of simply halving both $R_{\mathrm{w}, \min }$ and $\beta$ on predicted nighttime fluxes. Doing so decreases the mismatch between modeled and measured fluxes in most cases, even though there still remains significant scatter. However, in one case (BM) predicted fluxes actually turn out to fit the measurements worse than with the original parameters, and in another case (VK) this only leads to a marginal improvement. This exercise highlights the potential for a significant overall improvement in $\mathrm{NH}_{3}$ flux predictions by optimizing these two parameters based on independent data from all four ecosystem types (grassland, arable, forest, and semi-natural ecosystems) used in the MNS parameterization. 


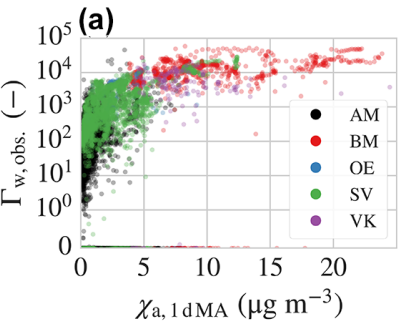

(b)

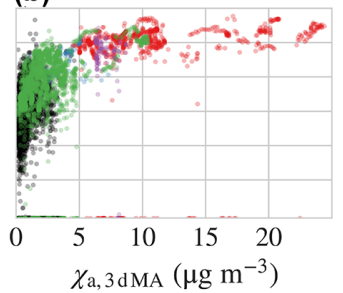

(c)

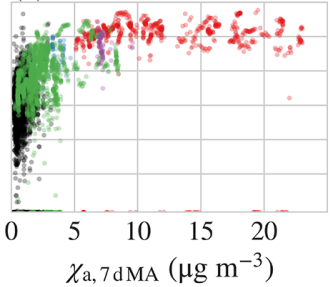

(d)

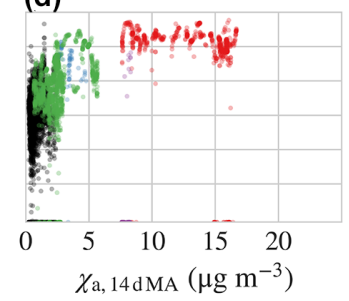

Figure 6. Non-stomatal emission potentials inferred from measurements $\left(\Gamma_{\mathrm{w}}\right)$ as a function of backward-looking moving averages of measured air ammonia concentrations $\left(\chi_{\mathrm{a}}\right)$. (a) 1 day, (b) 3 day, (c) 7 day, (d) 14 day moving window. Periods with substantial precipitation were removed from the analysis.
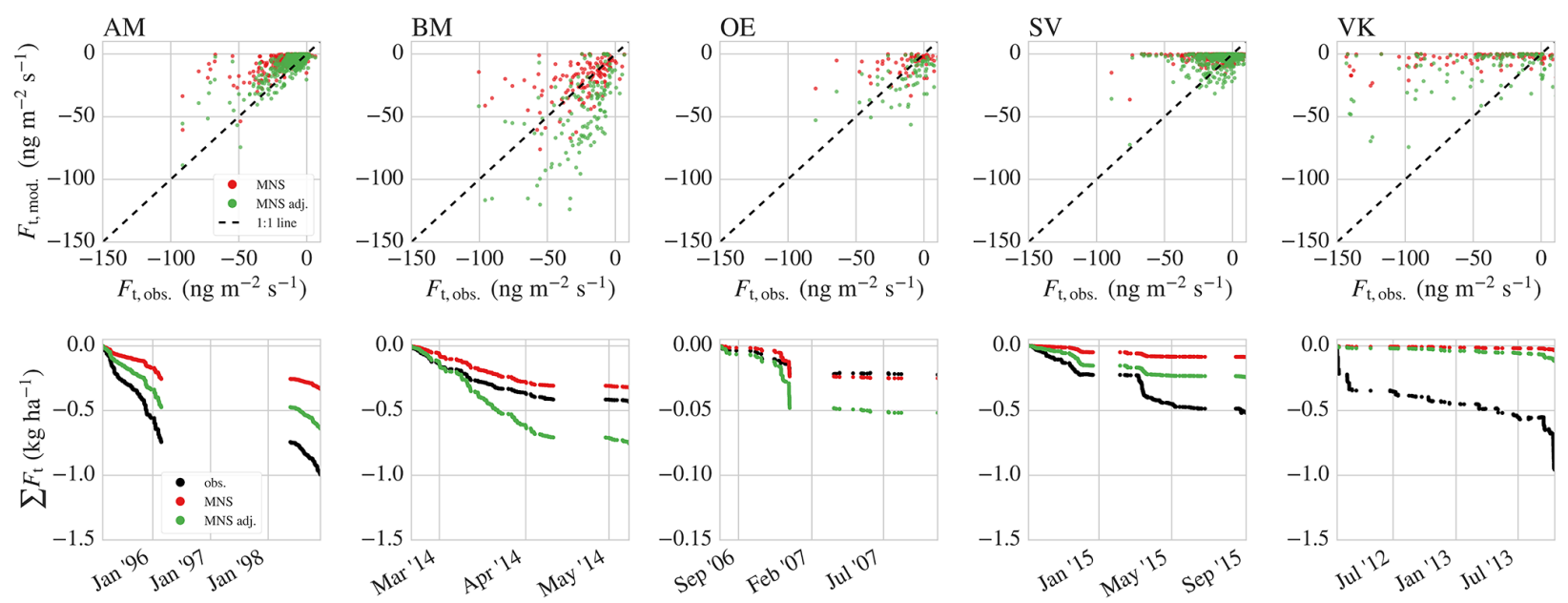

Figure 7. Measured and modeled ammonia dry deposition fluxes $\left(F_{\mathrm{t}}\right)$ during near-neutral or slightly stable nighttime conditions. (Upper row) Modeled vs. measured $6 \mathrm{~h}$ median flux densities. (Lower row) Cumulative fluxes. MNS adj. $=$ MNS with halved minimum $R_{\mathrm{W}}$ and temperature response parameter $\beta$.

\subsection{Sensitivity of the main findings}

Parts of both models used in this study were developed using an estimate of surface temperatures, either by extrapolating $T$ from the reference height $z-d$ to the notional height of trace gas exchange $z_{0}^{\prime}$ using sensible heat flux $H$ $\left(\mathrm{W} \mathrm{m}^{-2}\right.$ ) measurements, or by estimating $T\left\{z_{0}^{\prime}\right\}$ from outgoing long wave radiation measurements and the StefanBoltzmann law. Additionally, the temperature response function of Flechard et al. (2010), which is used within the MNS model, was fitted using surface level values of relative humidity $\operatorname{RH}\left\{z_{0}^{\prime}\right\}$, which were derived using measured latent heat fluxes LE (cf. Nemitz et al., 2009). Since $H$ and LE measurements were not available at all sites and introduce an additional source of uncertainty, especially during moderately stable nighttime conditions, and the WK model is routinely being used with air temperatures within the DEPAC3.11 code, here we used both $T$ and $\mathrm{RH}$ at the reference height as input data. Figure 8 (upper row) illustrates the effects of using $T$ and RH at different conceptual model heights for AM. While there are of course numerical differ- ences, they do not lead to significant differences in the main findings of this study. Generally, the WK model appears to be less sensitive to these choices than the MNS model.

For both SV and VK, no measurements of $\left[\mathrm{HNO}_{3}\right]$ and $[\mathrm{HCl}]$ were available. We estimated AR for the MNS model based on the observations of Fowler et al. (2009), which show that across NitroEurope sites $\left[\mathrm{SO}_{2}\right]$ makes up around $40 \%$ of the sum $\left[\mathrm{SO}_{2}\right]+\left[\mathrm{HNO}_{3}\right]+[\mathrm{HCl}]$ to be approximately 3.5 times the ratio of $\left[\mathrm{SO}_{2}\right] /\left[\mathrm{NH}_{3}\right]$. From the definitions $\mathrm{AR}=\left(2\left[\mathrm{SO}_{2}\right]+[\mathrm{HCl}]+\left[\mathrm{HNO}_{3}\right]\right) /\left[\mathrm{NH}_{3}\right]$ and $\mathrm{SN}=\left[\mathrm{SO}_{2}\right] /\left[\mathrm{NH}_{3}\right]$, a lower bound of $\mathrm{AR} \geq 2 \cdot \mathrm{SN}$ is obvious. Using a symmetrical range around our initial estimate of $\mathrm{AR} \approx 3.5 \cdot \mathrm{SN}$, we set an additional upper bound of $\mathrm{AR} \leq 5 \cdot \mathrm{SN}$ and tested the effects of using these values on $R_{\mathrm{W}}$ differences for both affected sites (Fig. 8, lower row). Again, there are apparent numerical differences, but they do not affect the main observations made here (i.e., they neither change the sign of the differences in modeled and measured $R_{\mathrm{w}}$, nor do they change the general magnitude of the differences, for example from a strong overestimation to an insignificant one). 

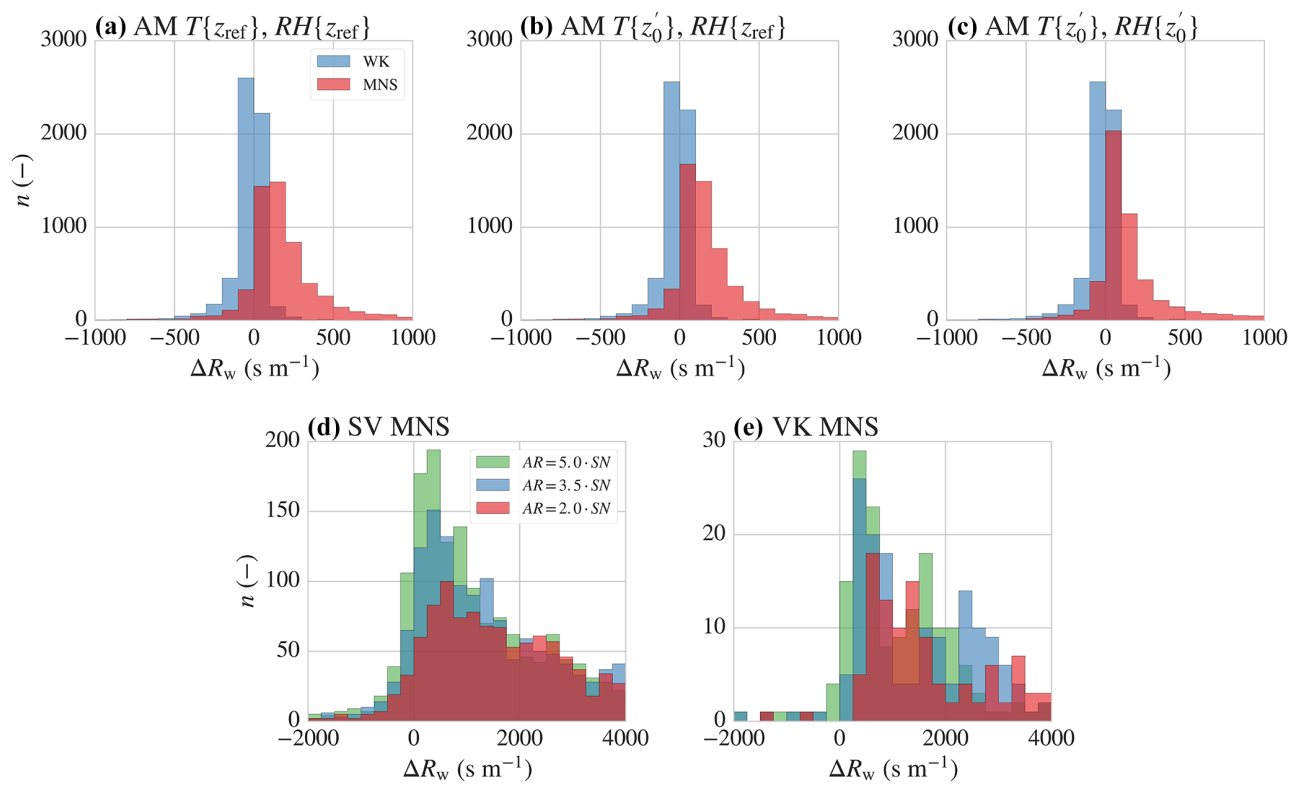

Figure 8. Sensitivity of differences in measured and modeled non-stomatal resistances to the use of measured air vs. surface temperature and relative humidity estimates. (Upper row) Exemplary calculations for AM with (a) $T$ and $\mathrm{RH}$ at the reference height, (b) $T$ at the notional height of trace gas exchange $\left(z_{0}^{\prime}\right)$, and (c) $T$ and $\mathrm{RH}$ at $z_{0}^{\prime}$. (Lower row) AR estimated as 2.0, 3.5, and 5.0 times the $\left[\mathrm{SO}_{2}\right] /\left[\mathrm{NH}_{3}\right] \mathrm{ratio}$ $\mathrm{SN}$ for (d) Solleveld and (e) Veenkampen. Note the asymmetric horizontal axis in (d, e). Data are binned into $100 \mathrm{~s} \mathrm{~m}^{-1}$ bins for (a-c) and $250 \mathrm{~s} \mathrm{~m}^{-1}$ bins for (d-e) to ensure visual clarity.

\subsection{Sources of uncertainty}

Nighttime $R_{\mathrm{w}, \mathrm{obs}}$. are affected by (i) the uncertainty in the flux measurements, which can be high due to insufficient turbulent mixing, and (ii) uncertainty in modeled $R_{\mathrm{a}}\{z-d\}$ and $R_{\mathrm{b}}$, which results from increasingly high stability corrections $\left(\Psi_{\mathrm{M}}\left\{\frac{z-d}{L}\right\}\right.$ and $\left.\Psi_{\mathrm{H}}\left\{\frac{z-d}{L}\right\}\right)$ under increasing atmospheric stability, possible inaccuracy of estimated $z_{0}$ and $d$, and possible inadequacy of the $R_{\mathrm{b}}$ model for some surfaces. We therefore emphasize that the results of this study are to be interpreted qualitatively and can only reveal overall tendencies in the models' accuracy, not provide a precise quantification of the mismatch between models and measurements. Propagation of these uncertainties through the analysis resulted in some negative values of $R_{\mathrm{w}, \mathrm{obs}}$. There are generally two possible reasons for negative canopy resistance values to occur: (i) emission (i.e., positive fluxes), or (ii) "overfast" deposition $\left(v_{\mathrm{d}}\{z-d\}>v_{\mathrm{d}, \max }\{z-d\}\right)$ that is not compatible with the resistance modeling framework used here. As a rule, we set an upper tolerance threshold for $v_{\mathrm{d}}\{z-d\}$ of $1.5 \cdot v_{\mathrm{d}, \max }\{z-d\}$, considered to be within the limits of nighttime flux measurement uncertainty and representing perfect sink behavior, and consequently set $R_{\mathrm{w}, \text { obs. }}$ to zero in these cases. Measurements where $v_{\mathrm{d}}\{z-d\}>1.5 \cdot v_{\mathrm{d}, \max }\{z-d\}$ were discarded and assumed to be either resulting from incompatibility with the atmospheric resistance $\left(R_{\mathrm{a}}\{z-d\}, R_{\mathrm{b}}\right)$ model or from measurement error. During emission events, $R_{\mathrm{w}, \text { obs. }}$ was set to infinity. Ranges from 2 to $16 \%$ invalid val- ues, 63 to $93 \%$ deposition and 4 to $29 \%$ emission were observed across the five sites during near-neutral nighttime conditions. The latter especially highlights the importance of further research towards a truly bidirectional paradigm for nonstomatal exchange (i.e., cuticular desorption, ground-based emissions, or emission fluxes from other environmental surfaces).

An additional investigation of daytime non-stomatal exchange would be beneficial in terms of a significant reduction of uncertainty in the observations and in order to cover a much wider range of temperatures and humidity regimes. However, comparisons based on daytime flux estimates were not made in this study so as not to introduce an additional source of bias via the stomatal pathway. Both Massad et al. (2010) and Wichink Kruit et al. (2010) also presented parameterizations for the stomatal emission potential, $\Gamma_{\mathrm{s}}(-)$. However, for MNS information about annual total (dry and wet) $\mathrm{N}$ input into the system is necessary. While this issue can be overcome by iteratively solving a model with more reactive nitrogen species so that $\mathrm{N}$ input is both a parameter and a result of the simulation, here we used a model that only predicts $\mathrm{NH}_{3}$ dry deposition, which we do not consider to be sufficient information to estimate total $\mathrm{N}$ input to our sites. At sites where total $\mathrm{N}$ input is known (e.g., BM, from Hurkuck et al. (2014), or from CTM results for other sites), the MNS and WK parameterizations both predict very different $\Gamma_{\mathrm{S}}$ estimates. The reasons for this mismatch have, to our knowledge, not been investigated to date. We therefore de- 
cided not to model the stomatal pathway explicitly and rely on nighttime fluxes only.

Explicitly modeling the stomatal pathway with physiologically accurate stomatal conductance models may have the additional benefit of being able to assess bias in the estimation of non-stomatal resistances introduced by nighttime stomatal opening, naturally resulting in a lower contribution of the non-stomatal pathway to the total observed flux. However, note that a distinction between physiological accuracy and the purpose for which the derived resistances are used has to be made. While nighttime stomatal opening is a well-known phenomenon (e.g., Caird et al., 2007), it is rarely respected in modeling studies (e.g., Fisher et al., 2007). A physiologically accurate $R_{\mathrm{w}}$ parameterization used in conjunction with a stomatal model that does not account for nighttime stomatal opening would result in biased fluxes. Here we derived $R_{\mathrm{W}}$ under the assumption that stomata are closed at night to ensure comparability with $R_{\mathrm{W}}$ values predicted by the WK and MNS parameterization, respectively, and compatibility with most operational biosphere-atmosphere exchange schemes, but we acknowledge that the physiological meaning may be confounded by stomatal flux contributions at night.

Another source of uncertainty lies in the fact that $R_{\mathrm{w}}$ models are often developed as "cuticular resistance" models with only leaf surface exchange in mind. However, in the one-layer resistance framework used here it is not possible to clearly differentiate between deposition towards or emission from wet leaf surfaces, leaf litter, the soil, stems and branches, and any other environmental surfaces. In fact, the MNS model was originally developed on the basis of the twolayer model of Nemitz et al. (2001), but outside of management events, the ground layer resistance was set to infinity in order to transform the model structure to that of a onelayer model (Massad et al., 2010). While it is indeed conceptually unsatisfactory to ignore the source/sink strength of the ground-layer, an unambiguous identification of multiple non-stomatal pathways' flux contributions by simply inverting the model and inferring resistances from meteorological measurements is not possible, unless there is a signal that can confidently be attributed to originate, for example, from the ground layer (after fertilizer application for instance). Therefore, due to these methodological limitations, both the parameterizations and the measurements of $R_{\mathrm{w}}$ discussed in this paper may very well integrate exchange fluxes with not only wet leaves, but also the soil, stems and branches, or other surfaces, for example.

\section{Conclusions}

We presented a semi-quantitative assessment of the compared performances of two state-of-the-art non-stomatal resistance parameterizations for ammonia biosphereatmosphere exchange models, supported by flux measure- ments from two semi-natural peatland and three grassland sites.

The unidirectional $R_{\mathrm{W}}$-only approach of Massad et al. (2010), which, in addition to the classical humidity response, reflects the effects of the air pollution climate, vegetation via the leaf area index, and an empirical temperature response, was found to overestimate $R_{\mathrm{W}}$ during nighttime at all five sites. Adjusting the temperature response and minimum $R_{\mathrm{w}}$ parameters in the MNS model towards smaller values resulted in a better match between modeled and measured $\mathrm{NH}_{3}$ fluxes at most, but not all sites. We suggest further investigating the potential of re-calibrating these parameters to flux data from all four ecosystem types represented in the MNS $R_{\mathrm{W}}$ parameterization. Compared to measured values found in the literature (e.g., Massad et al., 2010, Table 1), the minimum predicted $R_{\mathrm{W}}$ appears too high at sites with low atmospheric acid-to-ammonia ratios.

The quasi-bidirectional model of Wichink Kruit et al. (2010) shows a more complex response to varying air pollution climates and meteorological conditions, with both a tendency to underestimate $R_{\mathrm{w}}$, as initially hypothesized, during warm conditions and moderately high ambient $\mathrm{NH}_{3}$ concentrations, and a tendency to overestimate $R_{\mathrm{w}}$ during colder conditions, with an even stronger response to increasing $\chi_{\mathrm{a}}$. While there is likely no simple solution, as may be the case for the MNS model, the WK parameterization with its nonstomatal compensation point approach appears to be conceptually more compatible with field observations (e.g., morning peaks of $\mathrm{NH}_{3}$ emission due to evaporation of leaf surface water). We suggest revisiting the $\Gamma_{\mathrm{w}}$ parameterization with additional data from other ecosystems and investigating alternative approaches to model the effects of seasonality in $\Gamma_{\mathrm{w}}$, e.g., by using a smoothed temperature response instead of an instantaneous one. An extension of the model with an $\mathrm{SO}_{2}$ co-deposition response is currently being researched.

A simple alternative approach to dynamic models for the non-stomatal emission potential revealed a clear response of $\Gamma_{\mathrm{w}}$ to backward-looking moving averages of $\chi_{\mathrm{a}}$. These findings may turn out to be promising for CTMs, as they provide a first step towards a simplification of computationally intensive mechanistic models. However, further noise reduction, especially in the low concentration region, is needed for it to be useful for predicting $\mathrm{NH}_{3}$ exchange fluxes.

\section{Code and data availability}

Python 2.7 code for the resistance model parameterized after Massad et al. (2010) and Wichink Kruit et al. (2010), as well as the data analysis code, can be requested from the lead author via email (frederik.schrader@thuenen.de). Measurement data from AM, BM, and OE are property of the respective authors (cf. Table 1); for the SV and VK datasets, please contact M. C. van Zanten (margreet.van.zanten@ rivm.nl). 


\section{The Supplement related to this article is available online at doi:10.5194/acp-16-13417-2016-supplement.}

Acknowledgements. We greatly acknowledge funding of this work by the German Federal Ministry of Education and Research (BMBF) within the junior research group NITROSPHERE under support code FKZ 01LN1308A. The authors are grateful to all scientific and technical staff involved in gathering the data used in this study. Many thanks to R.-S. Massad for her helpful comments and clarifications during the early stages of developing the program code used for the flux calculations. We are grateful to C. Ammann for his valuable comments on the manuscript and his contribution to the OE dataset. Finally, we would like to thank L. Zhang for handling the manuscript and the three anonymous referees for their constructive reviews.

Edited by: L. Zhang

Reviewed by: three anonymous referees

\section{References}

Ball, J. T., Woodrow, I. E., and Berry, J. A.: A Model Predicting Stomatal Conductance and its Contribution to the Control of Photosynthesis under Different Environmental Conditions, in: Progress in Photosynthesis Research, edited by: Biggins, J., Springer Netherlands, Dordrecht, 221-224, doi:10.1007/978-94017-0519-6_48, 1987.

Burkhardt, J., Flechard, C. R., Gresens, F., Mattsson, M., Jongejan, P. A. C., Erisman, J. W., Weidinger, T., Meszaros, R., Nemitz, E., and Sutton, M. A.: Modelling the dynamic chemical interactions of atmospheric ammonia with leaf surface wetness in a managed grassland canopy, Biogeosciences, 6, 67-84, doi:10.5194/bg-667-2009, 2009.

Caird, M. A., Richards, J. H., and Donovan, L. A.: Nighttime Stomatal Conductance and Transpiration in C3 and C4 Plants, Plant Physiol., 143, 4-10, doi:10.1104/pp.106.092940, 2007.

Cape, J. N., Jones, M. R., Leith, I. D., Sheppard, L. J., van Dijk, N., Sutton, M. A., and Fowler, D.: Estimate of annual $\mathrm{NH}_{3}$ dry deposition to a fumigated ombrotrophic bog using concentrationdependent deposition velocities, Atmos. Environ., 42, 66376646, doi:10.1016/j.atmosenv.2008.04.027, 2008

Emberson, L., Ashmore, M., Cambridge, H. M., Simpson, D., and Tuovinen, J.-P.: Modelling stomatal ozone flux across Europe, Environ. Pollut., 109, 403-413, doi:10.1016/S02697491(00)00043-9, 2000.

Erisman, J. W. and Wyers, G. P.: Continuous measurements of surface exchange of $\mathrm{SO}_{2}$ and $\mathrm{NH}_{3}$; Implications for their possible interaction in the deposition process, Atmos. Environ. A-Gen., 27, 1937-1949, doi:10.1016/0960-1686(93)90266-2, 1993.

Erisman, J. W., Van Pul, A., and Wyers, P.: Parametrization of surface resistance for the quantification of atmospheric deposition of acidifying pollutants and ozone, Atmos. Environ., 28, 25952607, doi:10.1016/1352-2310(94)90433-2, 1994.

Erisman, J. W., Mosquera, J., and Hensen, A.: Two options to explain the ammonia gap in The Netherlands, Environ. Sci. Pol., 4, 97-105, doi:10.1016/S1462-9011(00)00115-5, 2001.
Erisman, J. W., Galloway, J. N., Seitzinger, S., Bleeker, A., Dise, N. B., Petrescu, A. M. R., Leach, A. M., and de Vries, W.: Consequences of human modification of the global nitrogen cycle, Philos. T. R. Soc. B, 368, 20130116, doi:10.1098/rstb.2013.0116, 2013.

Famulari, D., Fowler, D., Hargreaves, K., Milford, C., Nemitz, E., Sutton, M. A., and Weston, K.: Measuring Eddy Covariance Fluxes of Ammonia Using Tunable Diode Laser Absorption Spectroscopy, Water Air Soil Poll., 4, 151-158, doi:10.1007/s11267-004-3025-1, 2004.

Farquhar, G. D. and Sharkey, T. D.: Stomatal Conductance and Photosynthesis, Annu. Rev. Plant Physiol., 33, 317-345, doi:10.1146/annurev.pp.33.060182.001533, 1982.

Farquhar, G. D., Firth, P. M., Wetselaar, R., and Weir, B: On the Gaseous Exchange of Ammonia between Leaves and the Environment: Determination of the Ammonia Compensation Point, Plant Physiol., 66, 710-714, doi:10.1104/pp.66.4.710, 1980.

Ferrara, R. M., Loubet, B., Di Tommasi, P., Bertolini, T., Magliulo, V., Cellier, P., Eugster, W., and Rana, G.: Eddy covariance measurement of ammonia fluxes: Comparison of high frequency correction methodologies, Agr. Forest Meteorol., 158-159, 3042, doi:10.1016/j.agrformet.2012.02.001, 2012.

Fisher, J. B., Baldocchi, D. D., Misson, L., Dawson, T. E., and Goldstein, A. H.: What the towers don't see at night: notcturnal sap flow in trees and shrubs at two AmeriFlux sites in California, Tree Physiol., 27, 596-610, doi:10.1093/treephys/27.4.597, 2007.

Flechard, C. R., Fowler, D., Sutton, M. A., and Cape, J. N.: A dynamic chemical model of bi-directional ammonia exchange between semi-natural vegetation and the atmosphere, Q. J. Roy. Meteorol. Soc., 125, 2611-2641, doi:10.1002/qj.49712555914, 1999.

Flechard, C. R., Spirig, C., Neftel, A., and Ammann, C.: The annual ammonia budget of fertilised cut grassland -Part 2: Seasonal variations and compensation point modeling, Biogeosciences, 7 , 537-556, doi:10.5194/bg-7-537-2010, 2010.

Flechard, C. R., Massad, R.-S., Loubet, B., Personne, E., Simpson, D., Bash, J. O., Cooter, E. J., Nemitz, E., and Sutton, M. A.: Advances in understanding, models and parameterizations of biosphere-atmosphere ammonia exchange, Biogeosciences, 10, 5183-5225, doi:10.5194/bg-10-5183-2013, 2013.

Fowler, D., Pilegaard, K., Sutton, M. A., Ambus, P., Raivonen, M., Duyzer, J., Simpson, D., Fagerli, H., Fuzzi, S., Schjoerring, J. K., Granier, C., Neftel, A., Isaksen, I. S. A., Laj, P., Maione, M., Monks, P. S., Burkhard, J., Dämmgen, U., Neirynck, J., Personne, E., Wichink Kruit, R., Butterbach-Bahl, K., Flechard, C., Tuovinen, P., Coyle, M., Gerosa, G., Loubet, B., Altimir, N., Grünhage, L., Ammann, C., Cieslik, S., Paoletti, E., Mikkelsen, T. N., Ro-Poulsen, H., Cellier, P., Cape, J. N., Horvath, L., Loreto, F., Niinemets, Ü., Palmer, P. I., Rinne, J., Misztal, P., Nemitz, E., Nilsson, D., Pryor, S., Gallagher, M. W., Vesala, T., Skiba, U., Brüggemann, N., Zechmeister-Boltenstern, S., Williams, J., O'Dowd, C., Facchini, M. C., de Leeuw, G., Flossman, A., Chaumerliac, N., and Erisman, J. W.: Atmospheric composition change: Ecosystems-Atmosphere interactions, Atmos. Environ., 43, 5193-5267, doi:10.1016/j.atmosenv.2009.07.068, 2009.

Garland, J. A.: The Dry Deposition of Sulphur Dioxide to Land and Water Surfaces, Proceedings of the Royal Society A: Mathemati- 
cal, Phys. Eng. Sci., 354, 245-268, doi:10.1098/rspa.1977.0066, 1977

Hurkuck, M., Brümmer, C., Mohr, K., Grünhage, L., Flessa, H., and Kutsch, W. L.: Determination of atmospheric nitrogen deposition to a semi-natural peat bog site in an intensively managed agricultural landscape, Atmos. Environ., 97, 296-309, doi:10.1016/j.atmosenv.2014.08.034, 2014.

Jarvis, P. G.: The Interpretation of the Variations in Leaf Water Potential and Stomatal Conductance Found in Canopies in the Field, Philos. T. R. Soc. B, 273, 593-610, doi:10.1098/rstb.1976.0035, 1976.

Jones, M. R., Leith, I. D., Fowler, D., Raven, J. A., Sutton, M. A., Nemitz, E., Cape, J. N., Sheppard, L. J., Smith, R. I., and Theobald, M. R.: Concentration-dependent $\mathrm{NH}_{3}$ deposition processes for mixed moorland semi-natural vegetation, Atmos. Environ., 41, 2049-2060, doi:10.1016/j.atmosenv.2006.11.003, 2007a.

Jones, M. R., Leith, I. D., Raven, J. A., Fowler, D., Sutton, M. A., Nemitz, E., Cape, J. N., Sheppard, L. J., and Smith, R. I.: Concentration-dependent $\mathrm{NH}_{3}$ deposition processes for moorland plant species with and without stomata, Atmos. Environ., 41, 8980-8994, doi:10.1016/j.atmosenv.2007.08.015, $2007 \mathrm{~b}$.

Massad, R.-S., Nemitz, E., and Sutton, M. A.: Review and parameterisation of bi-directional ammonia exchange between vegetation and the atmosphere, Atmos. Chem. Phys., 10, 10359-10386, doi:10.5194/acp-10-10359-2010, 2010.

Milford, C., Hargreaves, K. J., Sutton, M. A., Loubet, B., and Cellier, P.: Fluxes of $\mathrm{NH}_{3}$ and $\mathrm{CO}_{2}$ over upland moorland in the vicinity of agricultural land, J. Geophys. Res.-Atmos., 106, 24169-24181, doi:10.1029/2001JD900082, 24169-24181, 2001.

Móring, A., Vieno, M., Doherty, R. M., Laubach, J., TaghizadehToosi, A., and Sutton, M. A.: A process-based model for ammonia emission from urine patches, GAG (Generation of Ammonia from Grazing): description and sensitivity analysis, Biogeosciences, 13, 1837-1861, doi:10.5194/bg-13-1837-2016, 2016.

Neirynck, J. and Ceulemans, R.: Bidirectional ammonia exchange above a mixed coniferous forest, Environ. Pollut., 154, 424-438, doi:10.1016/j.envpol.2007.11.030, 2008.

Nemitz, E., Sutton, M. A., Schjoerring, J. K., Husted, S., and Wyers, G. P.: Resistance modelling of ammonia exchange over oilseed rape, Agr. Forest Meteorol., 105, 405-425, doi:10.1016/S01681923(00)00206-9, 2000.

Nemitz, E., Milford, C., and Sutton, M. A.: A two-layer canopy compensation point model for describing bi-directional biosphere-atmosphere exchange of ammonia, Q. J. Roy. Meteor. Soc., 127, 815-833, doi:10.1002/qj.49712757306, 2001.

Nemitz, E., Hargreaves, K. J., Neftel, A., Loubet, B., Cellier, P., Dorsey, J. R., Flynn, M., Hensen, A., Weidinger, T., Meszaros, R., Horvath, L., Dämmgen, U., Frühauf, C., Löpmeier, F. J., Gallagher, M. W., and Sutton, M. A.: Intercomparison and assessment of turbulent and physiological exchange parameters of grassland, Biogeosciences, 6, 1445-1466, doi:10.5194/bg-61445-2009, 2009.

Paulson, C. A.: The Mathematical Representation of Wind Speed and Temperature Profiles in the Unstable Atmospheric Surface Layer, J. Applied Meteorol., 9, 857-861, doi:10.1175/15200450(1970)009<0857:TMROWS>2.0.CO;2, 1970.
Shen, J., Chen, D., Bai, M., Sun, J., Coates, T., Lam, S. K., and Li, Y.: Ammonia deposition in the neighbourhood of an intensive cattle feedlot in Victoria, Australia, Scientific Reports, 6, 32793, doi:10.1038/srep32793, 2016.

Spirig, C., Flechard, C. R., Ammann, C., and Neftel, A.: The annual ammonia budget of fertilised cut grassland - Part 1: Micrometeorological flux measurements and emissions after slurry application, Biogeosciences, 7, 521-536, doi:10.5194/bg-7-5212010, 2010.

Sutton, M. A. and Fowler, D.: A model for inferring bi-directional fluxes of ammonia over plant canopies, in: WMO Conference on the Measurement and Modeling of Atmospheric Composition Changes including Pollution Transport, WMO/GAW, WMO, Geneva, CH, Sofia, Bulgaria, 179-182, 1993.

Sutton, M. A., Schjorring, J. K., Wyers, G. P., Duyzer, J. H., Ineson, P., and Powlson, D. S.: Plant-Atmosphere Exchange of Ammonia [and Discussion], Philos. T. R. Soc. A, 351, 261-278, doi:10.1098/rsta.1995.0033, 1995.

Sutton, M. A., Burkhardt, J. K., Guerin, D., Nemitz, E., and Fowler, D.: Development of resistance models to describe measurements of bi-directional ammonia surface-atmosphere exchange, Atmos. Environ., 32, 473-480, doi:10.1016/S13522310(97)00164-7, 1998.

Sutton, M. A., Howard, C. M., Erisman, J. W., Billen, G., Bleeker, A., Grennfelt, P., van Grinsven, H., and Grizzetti, B. (Eds.): The European Nitrogen Assessment: Sources, Effects and Policy Perspectives, Cambridge University Press, Cambridge, UK, 664 pp., 2011.

Sutton, M. A., Reis, S., Riddick, S. N., Dragosits, U., Nemitz, E., Theobald, M. R., Sim Tang, Y., Braban, C. F., Vieno, M., Dore, A. J., Mitchell, R. F., Wanless, S., Daunt, F., Fowler, D., Blackall, T. D., Milford, C., Flechard, C. R., Loubet, B., Massad, R., Cellier, P., Personne, E., Coheur, P. F., Clarisse, L., Van Damme, M., Ngadi, Y., Clerbaux, C., Skjoth, C. A., Geels, C., Hertel, O., Wichink Kruit, R. J., Pinder, R. W., Bash, J. O., Walker, J. T., Simpson, D., Horvath, L., Misselbrook, T. H., Bleeker, A., Dentener, F., and de Vries, W.: Towards a climate-dependent paradigm of ammonia emission and deposition, Philos. T. Roy. Soc. B, 368, 20130166, doi:10.1098/rstb.2013.0166, 2013.

van Zanten, M. C., Sauter, F. J., Wichink Kruit, R. J., van Jaarsveld, J. A., and van Pul, W. A. J.: Description of the DEPAC module; Dry deposition modeling with DEPAC_GCN2010, National Institute for Public Health and the Environment (RIVM), Bilthoven, the Netherlands, 2010.

Volten, H., Bergwerff, J. B., Haaima, M., Lolkema, D. E., Berkhout, A. J. C., van der Hoff, G. R., Potma, C. J. M., Wichink Kruit, R. J., van Pul, W. A. J., and Swart, D. P. J.: Two instruments based on differential optical absorption spectroscopy (DOAS) to measure accurate ammonia concentrations in the atmosphere, Atmos. Meas. Tech., 5, 413-427, doi:10.5194/amt-5-413-2012, 2012.

Webb, E. K.: Profile relationships: The log-linear range, and extension to strong stability, Q. J. Roy. Meteor. Soc., 96, 67-90, doi:10.1002/qj.49709640708, 1970.

Wesely, M.: Parameterization of surface resistances to gaseous dry deposition in regional-scale numerical models, Atmos. Environ., 23, 1293-1304, doi:10.1016/0004-6981(89)90153-4, 1989.

Wichink Kruit, R. J., van Pul, W. A. J., Otjes, R. P., Hofschreuder, P., Jacobs, A. F. G., and Holtslag, A. A. M.: Ammonia fluxes and derived canopy compensation points over non-fertilized agri- 
cultural grassland in The Netherlands using the new gradient ammonia-high accuracy-monitor (GRAHAM), Atmos. Environ., 41, 1275-1287, doi:10.1016/j.atmosenv.2006.09.039, 2007.

Wichink Kruit, R. J., van Pul, W. A. J., Sauter, F. J., van den Broek, M., Nemitz, E., Sutton, M. A., Krol, M., and Holtslag, A. A. M.: Modeling the surface-atmosphere exchange of ammonia, Atmos. Environ., 44, 945-957, doi:10.1016/j.atmosenv.2009.11.049, 2010.

Wichink Kruit, R. J., Schaap, M., Sauter, F. J., van Zanten, M. C., and van Pul, W. A. J.: Modeling the distribution of ammonia across Europe including bi-directional surface-atmosphere exchange, Biogeosciences, 9, 5261-5277, doi:10.5194/bg-9-52612012, 2012 .
Wyers, G. P. and Erisman, J. W: Ammonia exchange over coniferous forest, Atmos. Environ., 32, 441-451, doi:10.1016/S13522310(97)00275-6, 1998.

Zhang, L., Brook, J. R., and Vet, R.: A revised parameterization for gaseous dry deposition in air-quality models, Atmos. Chem. Phys., 3, 2067-2082, doi:10.5194/acp-3-2067-2003, 2003.

Zöll, U., Brümmer, C., Schrader, F., Ammann, C., Ibrom, A., Flechard, C. R., Nelson, D. D., Zahniser, M., and Kutsch, W. L.: Surface-atmosphere exchange of ammonia over peatland using QCL-based eddy-covariance measurements and inferential modeling, Atmos. Chem. Phys., 16, 11283-11299, doi:10.5194/acp16-11283-2016, 2016. 